\title{
KINERJA SEKRETARIS DESA DALAM PENYELENGGARAAN PEMERINTAHAN DESA: STUDI DI DESA CEMPAKA MULIA BARAT KECAMATAN CEMPAGA KABUPATEN KOTAWARINGIN TIMUR
}

\begin{abstract}
Abdul Hamid
ABSTRACT

This study aims to determine the Secretary of Village performance Cempaka Mulia Barat Village Administration In the Governing Village Cempaka Mulia Barat subdistrict Cempaga District Kotawaringin Timur. The focus of this research study to determine the performance secretary of the village using performance indicators of Anwar Prabu Mangkunegara the quality of work, quantity of work, execution of work and responsibility, as well as factors inhibiting and supporting factors of the performance of the secretary of the village. This research uses descriptive qualitative research method by conducting interviews with the chief, the village secretary, Village Consultative Body, Head of Public Affairs, Head of Government Affairs, Head of Development and Cempaka Mulia Barat Village People. Analysis of data using analytical models Bogdan and Biklen is sifting through the data into units that can be managed, synthesizing the data, search and find data patterns, find important data and learned and decide what can be told to others.
\end{abstract}

Keywords : Performance, Village Government

\section{LATAR BELAKANG}

Diangkatnya Sekretaris Desa menjadi Pegawai Negeri Sipil salah satunya bertujuan untuk memberikan apresiasi atas pengabdiannya selama ini. Karena Sekretaris Desa dianggap pejabat senior yang menguasai prosedur pekerjaan dan mengetahui seluk beluk Pemerintahan Desa, sebagian besar Sekretaris Desa menganggap bahwa kinerja yang dilakukan tidak banyak mempunyai pengaruh terhadap kinerja aparatur desa lainnya. Ini disebabkan oleh adanya distribusi pekerjaan yang tidak merata diantara Kepala Urusan Desa yang lain dengan Sekretaris Desa. Organisasi Sekretaris Desa yang selama ini dianggap lemah kinerjanya akan menghadapi tantangan tugas yang cukup besar, sehingga kewenangan yang besar akan melekat dalam diri Sekretaris Desa. Hal ini sebagai konsekuensi dari berbagai perubahan Politik dan Pemerintahan yang terjadi, dimana Kepala Desa dapat terekrut dari berbagai golongan yang tentunya akan membuka kemungkinan terekrutnya Kepala Desa yang kurang memahami seluk beluk Organisasi Pemerintahan Desa.

Pada Desa Cempaka Mulia Barat Kecamatan Cempaga Kabupaten Kotawaringin Timur, dengan melihat fisik pembangunan dan masyarakatnya kurang begitu memahami dan kurang aktif dalam hal perencanaan pembangunan desa namun untuk pelaksanaan pembangunan masyarakat desa ini cukup aktif dan cenderung memiliki kecemburuan sosial yang tinggi, hal tersebut dapat dilihat apabila RT atau RW yang warganya banyak mengikuti Musyawarah Rencana Pembangunan Desa (MusrenbangDes) sehingga di daerah RT/RW nya diadakan 
pembangunan maka RT/RW yang lain mengganggap Pemerintah Desa pilih kasih. Di satu sisi Kepala Desa Cempaka Mulia Barat sering sekali berurusan keluar desa dan sulit untuk ditemui, jadi Sekretaris Desa Cempaka Mulia Barat lah yang sering mengambil alih tugas-tugas Kepala Desa tersebut. Sekretaris Desa Cempaka Mulia Barat ini sudah lama berkecimpung di Pemerintahan Desa ini, sehingga dapat dikatakan Sekretaris Desa ini sudah cukup berpengalaman dalam Pemerintahan Desa. Namun melihat dari aspek pelayanan terhadap masyarakat, Sekretaris Desa sepertinya terlalu berhati-hati dalam memberikan pelayanannya dan cenderung tertutup dalam hal permasalahan yang dihadapinya. Permasalahan seperti kurang optimalnya Sumber Daya Manusia atau Kompetensi Aparat Pemerintah Desa, penguasaan teknologi Administrasi yang masih kurang, hubungan kerja yang tidak harmonis antar sesama Aparatur dan manajemen Birokrasi itu sendiri bisa saja terjadi pada Pemerintah Desa Cempaka Mulia Barat ini terlebih lagi Sekretaris Desa yang selama ini banyak menggantikan tugas Kepala Desa tersebut, sehingga peran dari Sekretaris Desa yang lebih banyak dalam Pemerintahan Desa ini.

Jadi menarik untuk di teliti bagaimanakah pelaksanaan tugas dan fungsi dari Sekretaris Desa ini, oleh karena itu peneliti berminat untuk menganalisis dan mendeskripsikan kinerja Sekretaris Desa Cempaka Mulia Barat ini, dan menggagas sebuah penelitian dengan judul "KINERJA SEKRETARIS DESA DALAMPENYELENGGARAAN PEMERINTAHAN DESA (Studi Di Desa Cempaka Mulia Barat Kecamatan Cempaga Kabupaten Kotawaringin Timur)

Dari latar belakang yang telah diuraikan diatas maka disini peneliti menyusun beberapa rumusan masalah sebagai acuan dalam melaksanakan penelitian yaitu : (1) Bagaimana Kinerja Sekretaris Desa dalam Penyelenggaraan Pemerintahan Desa Cempaka Mulia Barat Kecamatan Cempaga Kabupaten Kotawaringin Timur; (2) Apa Saja Faktor Penghambat dan Faktor Pendukung Kinerja Sekretaris Desa dalam Penyelenggaraan Pemerintahan Desa Cempaka Mulia Barat Kecamatan Cempaga Kabupaten Kotawaringin Timur.

\section{TINJAUAN PUSTAKA}

\section{Kinerja}

Pengertian kata "kinerja" secara umum dirangkum oleh Rivai dan Basri (2005: 14-16) dari berbagai sumber dan dijabarkan dalam pokok-pokok sebagai berikut: (1) Kinerja adalah seperangkat hasil yang dicapai dan merujuk pada tindakan pencapaian serta pelaksanaan sesuatu pekerjaan yang diminta (Stolovitch, Keeps: 1992); (2) Kinerja merupakan salah satu kumpulan total dari kerja yang ada pada diri pekerja (Griffin: 1987).

\section{Indikator Kinerja}

Anwar Prabu Mangkunegara (2009: 75) mengemukakan bahwa indikator kinerja, yaitu : (a) Kualitas, kualitas kerja adalah seberapa baik seorang karyawan mengerjakan apa yang seharusnya dikerjakan; (b) Kuantitas, kuantitas kerja adalah seberapa lama seorang pegawai bekerja dalam satu harian; (c) Pelaksanaan Tugas, pelaksanaan tugas adalah seberapa jauh karyawan mampu melakukan pekerjaannya dengan akurat atau tidak ada kesalahan; (d) Tanggung Jawab, tanggung jawab terhadap pekerjaan adalah kesadaran akan kewajiban karyawan untuk melaksanakan pekerjaan yang diberikan perusahaan. (Mangkunegara 2009: 75) 


\section{Pengertian Desa}

Dapat disimpulkan bahwa desa adalah suatu wilayah atau tempat yang didiami/ditinggali oleh sejumlah penduduk yang saling kenal karena memiliki hubungan kekerabatan/kekeluargaan dan saling mempunyai kepentingan baik politik, sosial, ekonomi dan keamanan dan dalam pertumbuhannya menjadi kesatuan masyarakat hukum berdasarkan adat istiadat sehingga tercipta ikatan lahir batin antara masing-masing warganya, umumnya warga hidup dari pertanian, mempunyai hak mengatur rumah tangga sendiri, dan secara administratif berada dibawah pemerintahan kabupaten/kota (Hanif Nurcholis 2002:4).

\section{Pemerintah Desa}

Hanif Nurcholis (2002:75) memaparkan bahwa penyelenggaraan pemerintah desa dilakukan oleh pemerintah desa dan Badan Permusyawaratan Desa (BPD). Pemerintah desa adalah organisasi yang terdiri atas : (1) Kepala Desa ; (2) Sekretaris Desa dan (3) Unsur pelaksana teknis.

\section{Sekretaris Desa}

Dalam Peraturan Menteri Dalam Negeri Republik Indonesia Nomor 84 tahun 2015 tentang Susunan Organisasi Dan Tata Kerja Pemerintah Desa menerangkan bahwa Sekretaris Desa adalah Perangkat Desa yang bertugas membantu Kepala Desa dalam bidang tertib administrasi pemerintahan dan pembangunan serta pelayanan dan pemberdayaan masyarakat.

\section{Tugas Dan Fungsi Sekretaris Desa}

Sesuai dengan Peraturan Menteri Dalam Negeri Republik Indonesia Nomor 84 tahun 2015 tentang susunan organisasi dan tata kerja pemerintah desa, Sekretaris desa berkedudukan sebagai unsur pimpinan Sekretariat Desa mempunyai tugas dan fungsi sebagai berikut: (1) Sekretaris Desa bertugas membantu Kepala Desa dalam bidang administrasi pemerintahan; (2) Melaksanakan urusan ketatausahaan; (3) Melaksanakan urusan umum; (4) Melaksanakan urusan keuangan; dan (5) Melaksanakan urusan perencanaan, melakukan monitoring dan evaluasi program, serta penyusunan laporan.

\section{METODE PENELITIAN}

\section{Jenis Penelitian}

Jenis penelitian yang digunakan peneliti yaitu penelitian kualitatif.

\section{Lokasi Penelitian}

Lokasi penelitian yang diambil yaitu di Desa Cempaka Mulia Barat Kecamatan Cempaga Kabupaten Kotawaringin Timur.

\section{Fokus Penelitian}

Fokus penelitian ini adalah (1) Kinerja Sekretaris Desa Cempaka Mulia Barat dalam Penyelenggaraan Pemerintahan Desa; (2) Faktor Penghambat dan Faktor Pendukung dari Kinerja Sekretaris Desa Cempaka Mulia Barat dalam Penyelenggaraan Pemerintahan Desa. 


\section{Sumber Data}

a. Data Primer adalah data yang diperoleh dari hasil observasi dan wawancara. Wawancara dilakukan kepada Aparatur Pemerintah Desa yaitu : 1) Kepala Desa. 2) Sekretaris Desa. 3) Ketua Badan Permusyawaratan Desa. 4) Kepala Urusan Desa. 5) Beberapa Warga Desa.

b. Data sekunder terdiri dari literatur dan dokumen-dokumen lain, dan juga hasilhasil penelitian orang lain yang mempunyai hubungan dengan kajian penelitian ini.

\section{Teknik Pengumpulan Data}

Adapun teknik pengumpulan data yang dilakukan peneliti dalam penelitian ini yaitu pengamatan/observasi, wawancara dan dokumentasi.

\section{Analisis Data}

Analisis data kualitatif (Bogdan \& Biklen, 1982) adalah upaya yang dilakukan dengan jalan bekerja dengan data, memilah-milahnya menjadi satuan yang dapat dikelola, mensitesiskannya, mencari dan menemukan pola, menemukan apa yang penting dan apa yang dipelajari serta memutuskan apa yang dapat diceritakan kepada orang lain.

\section{Keabsahan Data}

Menurut Moleong (2010: 330), triangulasi adalah teknik pemeriksaan keabsahan data yang memanfaatkan sesuatu yang lain di luar data itu untuk keperluan pengecekan atau sebagai pembanding terhadap data itu.

\section{HASIL PENELITIAN DAN PEMBAHASAN}

Berdasarkan hasil penelitian maka selanjutnya peneliti berusaha untuk mengkaji kinerja Sekretaris Desa dalam penyelenggaraan pemerintahan desa Cempaka Mulia Barat. Dalam kinerja terdapat indikator kinerja yang terdiri atas kualitas kerja, kuantitas kerja, pelaksanaan tugas dan tanggung jawab. (Mangkunegara, 2009:75). Bila konsep yang dijelaskan diatas dikaitkan dengan tugas dan fungsi Sekretaris Desa sebagaimana yang telah diatur dalam Peraturan Menteri Dalam Negeri Republik Indonesia Nomor 84 tahun 2015 tentang Susunan Organisasi Dan Tata Kerja Pemerintah Desa.

\section{Kualitas}

Berdasarkan wawancara dengan para narasumber, secara kualitas kerja yang dikerjakan oleh Sekretaris Desa Cempaka Mulia Barat sesuai dengan tugas dan fungsi yang diamanatkan oleh Peraturan Menteri Dalam Negeri Republik Indonesia Nomor 84 tahun 2015 tentang Susunan Organisasi Dan Tata Kerja Pemerintah Desa, secara keseluruhan sudah dikerjakan dengan baik, hanya saja masih peneliti temukan kekurangan yang dimiliki oleh Sekretaris Desa Cempaka Mulia Barat diantaranya, masih adanya kelemahan dari segi fasilitas yang belum dimiliki oleh Kepala Urusan Umum, kurang menguasainya Sekretaris Desa dalam pengoperasian komputer khususnya Microsoft Excel dan Microsoft Word, Kurangnya Koordinasi dan juga pembinaan terhadap Anggota Kepala Urusan Desa Cempaka Mulia Barat oleh Sekretaris Desa. Jadi jika dilihat dari pengertian Kualitas kerja yang telah dipaparkan diatas bahwa Peneliti menilai dari segi 
Kualitas kerja tersebut, bahwa Sekretaris Desa Cempaka Mulia Barat ini masih belum maksimal dalam mengerjakan tugasnya.

\section{Kuantitas}

Berdasarkan wawancara dengan para narasumber, secara kuantitas kerja Sekretaris Desa Cempaka Mulia Barat ini menurut peneliti sudah sesuai dengan tugas dan fungsi yang telah diuraikan, meskipun dalam prakteknya Sekretaris Desa juga pernah pulang lebih awal dari jam kerja Pegawai Negeri Sipil namun hal tersebut dikarenakan ada urusan mendadak, dan yang paling penting adalah kecepatan kerja bahwa Sekretaris Desa menyelesaikan pekerjaan biasanya lebih cepat dari target waktu. Jadi jika dikaitkan dengan pengertian kuantitas kerja Sekretaris Desa Cempaka Mulia Barat sudah bekerja sesuai kriteria tersebut dengan kata lain Sekretaris Desa Cempaka Mulia Barat dalam segi Kuantitas kerja sudah sesuai dengan tugas dan fungsinya yang diatur dalam Peraturan Menteri Dalam Negeri Republik Indonesia Nomor 84 tahun 2015 tentang Susunan Organisasi Dan Tata Kerja Pemerintah Desa.

\section{Pelaksanaan Tugas}

Berdasarkan wawancara dengan para narasumber, ditinjau dari pelaksanaan tugas yang dikerjakan oleh Sekretaris Desa Cempaka Mulia Barat, dalam pelaksanaan tugas dan fungsi, apabila dikaitkan dengan pengertian dari Pelaksanaan Tugas tersebut Peneliti melihat masih adanya kekurangan. Yang menguatkan pendapat peneliti tersebut yaitu, dimana masih adanya kesalahan atau kekeliruan yang sering dilakukan oleh Sekretaris Desa khususnya dalam hal pengetikan dan pengoperasian komputer.

\section{Tanggung Jawab}

Berdasarkan wawancara dengan para narasumber, ditinjau dari tanggung jawab yang dilakukan oleh Sekretaris Desa Cempaka Mulia Barat, dalam prakteknya kesadaran akan kewajiban Sekretaris Desa dalam melaksanakan tugas dan fungsinya secara keseluruhan Sekretaris Desa Cempaka Mulia Barat telah melaksanakan tugas dan fungsinya dengan penuh tanggung jawab.

Faktor penghambat dan faktor pendukung kinerja Sekretaris Desa dalam penyelenggaraan Pemerintahan Desa

\section{Faktor Penghambat}

Faktor penghambat sebagaimana disampaikan diatas meliputi faktor internal dan faktor eksternal dari Pemerintah Desa Cempaka Mulia Barat, faktor internal dari penghambat ini adalah terbatasnya fasilitas seperti laptop dan printer yang belum dimiliki oleh Kepala Urusan Umum dan sering sekali terjadi kesalahan pengetikan yang dialami oleh Sekretaris Desa. Sedangkan faktor penghambat eksternalnya adalah kurang maksimalnya dukungan dari Masyarakat Desa Cempaka Mulia Barat dalam hal penyelenggaraan pemerintahan, masyarakat cenderung pasif kurang terlalu aktif dalam hal tersebut. Sedangkan faktor penghambat yang dialami oleh peneliti adalah suasana kekerabatan yang amat kental dari para informan, dimana para informan lebih cenderung mengutarakan kelebihan dari Sekretaris Desa Cempaka Mulia Barat ini, sangat sedikit informasi 
mengenai kekurangan dari Sekretaris Desa tersebut, mungkin karena sistem kekerabatan yang terjalin di desa dan mungkin pula para informan takut terjadi perselisihan antara mereka dengan Sekretaris Desa tersebut. Peneliti juga mengalami kendala karena para informan dari kalangan Aparatur Desa tersebut sulit untuk ditemui karena mereka biasanya ada kesibukan baik dari kesibukan tugas maupun urusan keluarga. Untuk faktor penghambat dari Pemerintahan Desa Cempaka Mulia Barat ini Peneliti menilai bahwa Masyarakat kurang berperan aktif dalam hal perencanaan pembangunan desa, karena kurangnya kesadaran dan pengetahuan akan pentingnya keikut sertaan Masyarakat dan juga kurang baiknya pendekatan pemerintah desa terhadap masyarakatnya

\section{Faktor Pendukung}

Peneliti melihat bahwa ada beberapa faktor yang mendukung kinerja Sekretaris Desa tersebut. Diantaranya, sudah ada Kepala Desa yang berkompeten dalam menopang kinerja Sekretaris Desa apabila mengalami kesulitan, para Kaur yang selalu bekerja sesuai apa yang diperintahkan oleh atasan mereka dan tidak kalah pentingnya tidak ada konflik internal yang terjadi di Pemerintahan Desa Cempaka Mulia Barat serta dukungan dari masyarakat Desa Cempaka Mulia Barat.

\section{KESIMPULAN DAN SARAN}

\section{Kesimpulan}

Peneliti menarik kesimpulan sebagai berikut (1) Kinerja Sekretaris Desa dalam penyelenggaraan Pemerintahan desa Cempaka Mulia Barat secara Kualitas kerja masih belum maksimal yakni masih ditemukan kelemahan pada bidang pengusaan komputer yang masih kurang, kurangnya koordinasi dan juga pembinaan terhadap anggota Kepala Urusan oleh Sekretaris Desa. Secara Kuantitas kerja, Sekretaris Desa sudah menjalankannya dengan baik dimana Sekretaris Desa biasanya menyelesaikan pekerjaannya cepat sebelum waktu yang ditentukan dan Sekretaris Desa Cempaka Mulia Barat ini selalu hadir dan bertugas di kantor setiap harinya pada jam kerja. Dalam Pelaksanaan Tugas, Sekretaris Desa Cempaka Mulia Barat masih belum maksimal dalam pengerjaannya, hal ini dapat dilihat dari kurang menguasainya Sekretaris Desa dalam bidang pengoperasiaan komputer. Dalam Tanggung Jawab kerja, Sekretaris Desa Cempaka Mulia Barat mengerjakan segala tugas dan fungsinya dengan baik dan penuh tangung jawab terlihat dari selalu hadir dan bertugasnya Sekretaris Desa setiap hari kerja di kantor desa. (2) Kinerja Sekretaris Desa dalam penyelenggaraan Pemerintahan Desa, faktor penghambat terbagi menjadi dua bagian yaitu faktor penghambat internal yaitu berasal dari dalam Pemerintahan Desa, dan faktor penghambat eksternal yaitu kurang mendukungnya sebagian masyarakat dalam hal perencanaan pembangunan Desa. Sedangkan faktor pendukung/pendorong dari kinerja Sekretaris Desa ini adalah mendapat dukungan penuh dari Kepala Desa dan Para Kepala Urusan serta fasilitas pribadi Sekretaris Desa yang lengkap.

\section{Saran}

Peneliti merekomendasikan sebuah saran yaitu (1) Kinerja Sekretaris Desa dalam segi kualitas dan pelaksanaan tugas yang dikerjakan oleh Seketaris Desa Cempaka Mulia Barat harus dibenahi dengan cara memperbanyak mengikuti 
bimbingan teknis dan pelatihan-pelatihan yang berhubungan dengan pengoperasian komputer dan pembinaan Kepala Urusan. Diharapkan Pemerintah Daerah mengadakan petugas yang ahli dibidang komputer di Desa Cempaka Mulia Barat, sehingga dapat mempermudah urusan-urusan Pemerintah Desa Cempaka Mulia Barat. (2) Perlunya dukungan penuh dari masyarakat desa dalam hal perencanaan pembangunan dan pemerintahan, selain menambah kapasitas kinerja Sekretaris Desa, tidak akan maksimal jalannya pemerintahan tanpa dukungan penuh dari masyarakat desa tersebut dan Pemerintah Desa juga mampu membangkitkan semangat masyarakat desa agar aktif ikut ambil bagian dalam perencanaan pembangunan desa.

\section{DAFTAR PUSTAKA}

Fahmi, Irham. 2013, Manajemen Kinerja, Bandung: Alfabeta

Karlina, Nina. 2014. Pengangkatan Sekretaris Desa Menjadi Pns Dalam Mendukung Penyelenggaraan Pemerintahan Desa, Jurnal Skripsi diakses pada 28 Maret 2016, dari situs World Wide Web http://www.ejurnal.com//pengangkatan-sekretaris-desa-menjadi.html

Kaswan. 2013, Pelatihan dan Pengembangan Untuk Meningkatkan Kinerja SDM, Bandung: Alfabeta

Lexy, Moleong. 2004, Metodologi Penelitian Kualitatif, Bandung : Pt Remaja Rosda Karya

Mangkunegara, Prabu A. 2013, Manajemen Sumber Daya Manusia Perusahaan, Bandung : Pt Remaja Rosda Karya

Nurcholis, Hanif. 2011, Pertumbuhan dan Penyelenggaraan Pemerintahan Desa, Jakarta : Penerbit Erlangga

Peraturan Menteri Dalam Negeri Republik Indonesia Nomor 84 Tahun 2015 Tentang Susunan Organisasi Dan Tata Kerja Pemerintah Desa

Peraturan Pemerintah Republik Indonesia Nomor 72 Tahun 2005 Tentang Desa.

Satori, Djam'an \& Komariah, Aan. 2012, Metodologi Penelitian Kualitatif, Bandung: Alfabeta

Simanjuntak, Payaman J. 2005, Manajemen dan Evaluasi Kerja, Jakarta: Lembaga Penerbit FEUI

Sinambela, Poltak L. 2012, Kinerja Pegawai, Yogyakarta: Graha IlmuWidjaja, HAW. 2012, Otonomi Desa, Jakarta: PT RajaGrafindo Persada

Syah, Alam. 2014. Peran Sekretaris Desa Dalam Membantu Kepala Desa, Jurnal Skripsi diakses pada 01 April 2016, dari situs World Wide Webhttp://jurnal.umrah.ac.id/wp-content/uploads/gravity_forms/1 ec61c9cb232a03a96d0947c6478e525e/2014/08/E-Journal-ALAMSYAH.pdf 